\title{
Interventional procedures for cancer pain management
}

\author{
Procedimentos intervencionistas para o manejo da dor no câncer
}

\author{
Fabiola Peixoto Minson ${ }^{1}$, Fabrício Dias Assis², Thais Kfouri Vanetti², Jamir Sardá Junior ${ }^{3}$, \\ Wanessa Pereira Mateus ${ }^{1}$, Auro Del Giglio ${ }^{1}$
}

\begin{abstract}
Objective: To describe types of interventional medical procedures, its rationale use and benefits for a population with cancer assisted at a private hospital in São Paulo. Methods: Quantitative and descriptive cross-sectional study using data from patients submitted to interventional procedures between 2007 and 2008. We used descriptive and inferential statistics (frequency, mean, and $t$-test) to analyze data. Results: A total of 137 patients were submitted to interventional procedures for pain and, out of this total, 14 mentioned cancer-related pain. The mean pain intensity was 7.1 before the procedure and 1.3 after it. Reduction in pain intensity was statistically significant in this population $(t=9.09 ; p=0.001)$. In almost $70 \%$ of patients $(n=10)$ a reduction of $50 \%$ of the consumption of opioid a month after the procedure was realized. Conclusion: These results are in accordance with the literature and support the efficacy of interventional procedures for several types of cancer pain.
\end{abstract}

Keywords: Pain/drug therapy; Analgesics/therapeutic use; Neoplasms

\section{RESUMO}

Objetivo: Descrever tipos de procedimentos (seu uso racional e alguns de seus benefícios) realizados em pacientes com câncer tratados em um hospital privado de São Paulo. Métodos: Estudo quantitativo de corte transversal, que usou informações oriundas dos prontuários de pacientes submetidos a procedimentos intervencionistas para dor durante os anos de 2007 e 2008. Os dados foram analisados por meio de estatística descritiva e inferencial (frequência e média, e teste $t$ ). Resultados: Durante esse período, 137 pacientes foram submetidos a procedimentos intervencionistas para a dor e, desse total, 14 possuíam dores de natureza oncológica. A intensidade média da dor nos pacientes tratados foi de 7,1 antes do procedimento e, após, 1,3. A redução da dor foi estatisticamente significativa nessa população $(t=9,09 ; p=0,001)$. Em cerca de $70 \%$ dos pacientes $(n=10)$, houve redução de $50 \%$ no uso de opioide 1 mês após a realização do procedimento. Conclusão: Estes resultados estão de acordo com a literatura e confirmam a eficácia dos procedimentos intervencionistas para diversos tipos de dor oncológica.

Descritores: Dor/quimioterapia; Analgésicos/uso terapêutico; Neoplasias

\section{INTRODUCTION}

Each year more than 10 million people worldwide are diagnosed with cancer, and 70 to $90 \%$ of them will experience pain during the course of the disease ${ }^{(1)}$. The treatment of cancer usually does not treat only the disease, but also the pain associated with the picture because pain can affect the patients' quality of life ${ }^{(2-4)}$.

Patients with cancer-related pain often experience more than one type of pain (neuropathic, nociceptive or mixed pain) that could be constant or intermittent. Cancer-related pain can be caused by several mechanisms as direct tumor invasion (local and systemic), response to therapy or to the cancer diagnosis (surgery, chemotherapy or radiotherapy, and biopsy), or to noncancer related problems like disc hernia and diabetic neuropathy ${ }^{(3,5,6)}$. In addition, psychosocial factors as depression, anxiety, catastrophizing and cognition can influence the patient's perception of pain and contribute to total intensity of pain ${ }^{(7)}$.

In general, cancer pain can be treated but it requires an appropriate multidisciplinary approach involving knowledge on the pain physiopathology, analgesic pharmacology and psychosocial issues management ${ }^{(3,8)}$. Drug therapy according to three-step analgesic ladder advocated by World Health Organization (WHO) is

\footnotetext{
Study carried out at Hospital Israelita Albert Einstein - HIAE, São Paulo (SP), Brazil.

${ }^{1}$ Hospital Israelita Albert Einstein - HIAE, São Paulo (SP), Brazil.

${ }^{2}$ Clínica Singular de Tratamento de Dor Campinas - Campinas (SP), Brazil.

${ }^{3}$ Associação Catarinense de Estudo da Dor - ACED, Florianópolis (SC), Brazil; Clínica Singular de Tratamento de Dor - Campinas (SP), Brazil.

Corresponding author: Fabiola Peixoto Minson - Avenida Albert Einstein, 671 - Morumbi - Zip code: 05651-901 - São Paulo (SP), Brazil - Phone: (55 11) 2151-3105 - E-mail: fabiola.peixoto@uol.com.br

Received on: Aug 15, 2011 - Accepted on: Feb 3, 2012
}

Conflicts of interest: none. 
the basis to cancer pain control ${ }^{(4,8)}$, however, several proposals suggest the review and amplification for the use of the WHO analgesic ladder ${ }^{(3,6,9)}$.

The treatment according to this ladder achieves 70 to $90 \%$ of efficacy in all types of cancer pain with the use of simple analgesic, opioids and oral adjuvants ${ }^{(6-8)}$. Alternative route of drug administration as parenteral and transdermal can improve the treatment efficacy ${ }^{(3,7,8)}$. However, about $10 \%$ of patients do not have good response to drug therapy due to several reasons. Therefore, some intervention techniques are needed as peripheral nerve blocks, chemical neurolysis, implantable systems for administration of opioids within a multimodal approach to pain ${ }^{(2,3,6,10)}$.

Interventional pain treatment is indicated when medicines did not promote effective analgesia based on the WHO analgesic ladder or, when adverse effects become intolerable ${ }^{(5-7,9-11)}$. Interventional treatments consist in several minimally invasive techniques to reduce pain using percutaneous techniques (as neuromodulatory and neuroablative), alone or together with other treatment modalities ${ }^{(3,6,7,11)}$.

Neuroablative and non-ablative techniques constitute the two main categories of minimally invasive procedures for cancer pain control. In neuroablative techniques the nervous system is not preserved and nociceptive pathways are surgically, chemically or thermally interrupted. In neuromodulatory or non-ablative techniques the nervous system is preserved. Neuromodulation is a dynamic inhibition of nociceptive pathways by the administration of opioids and other medicines by spinal route or by stimulation techniques. Such procedures improve the patient's quality of life and satisfaction.

Besides the lack of effective response to other treatments promoted by the WHO analgesic ladder some factors as pain site, pain type, cause, disease progress, emotional aspects and survival time are important criteria to define interventional techniques to be used to increase efficacy ${ }^{(7,9,12)}$.

It is estimated that less than $5 \%$ of cancer patients in developing countries have access to these forms of treatment. Interventional procedures have its efficacy confirmed and constitute important resources for pain control. However, restriction as lack of trained physicians, precarious structure, limited material and financial resources contribute to reduce the use of such options in the treatment of patients in developing nations ${ }^{10)}$.

\section{OBJECTIVE}

To describe the number and types of procedures done in the Interventional Medical Service for Pain at Hospital
Israelita Albert Einstein (HIAE), São Paulo, Brazil in cancer patients aiming to show the applicability of these procedures, and to justify these type of intervention as well as to observe the achieved benefits.

\section{METHODS}

Descriptive, qualitative and cross-sectional study with 14 cancer patients selected from a sample of 137 individuals treated between August 2007 and October 20008 at HIAE.

We collected data from the patients' clinical record, and used a visual numeric scale to measure the intensity of pain, which classified pain from 0 to $10^{(13)}$. This research was approved by Ethical Committee of HIAE, number 1314-11. All ethical procedures for research with human beings were followed.

\section{Statistical Analysis}

A descriptive and inferential statistics were used to describe the number and types of procedures. The intensity of pain decreased and the use of medicines were analyzed with the $t$ test using the software Package for the Social Sciences (SPSS) 11 version for Windows.

\section{RESULTS}

The results related to 14 cancer patients submitted to interventional procedures during the studied period. A total of 137 patients were treated and 262 interventional procedures were done for the treatment of pain.

The cancer patients mean age was 56 years (standard deviation $-\mathrm{SD}=19.63$ ), and most of them were women $(70 \%)$. The intensity of pain was assessed by using the visual numeric scale. The mean of intensity of pain was 7.1 points $(\mathrm{SD}=2.46)$ and after the procedure 1.3 points $(\mathrm{SD}=2.58)$. Reduction in the intensity of pain was statistically significant $(t=9.09 ; \mathrm{p}=0.001)$. From the total of patients treated for cancer-related pain, $71 \%$ had reduction of $50 \%$ in the consumption of opioids a month after the procedure (Table 1). The types of performed procedures are described in figure 1 .

The following procedures were done for the cancer patients: intrathecal drug infusion pump replacement $(14 ; 30.4 \%)$, pulsed or standard radiofrequency (5; $10.9 \%)$, chemical neurolysis $(4 ; 8.7 \%)$ and infusion of implantable analgesic system $(4 ; 8.7 \%)$. Data showed that most of performed procedures in this population aimed to propose alternative methods for drug administration. 
Table 1. Clinical and demographic characteristics of patients submitted to interventional procedures

\begin{tabular}{lcc}
\hline $\begin{array}{l}\text { Clinical and demographic } \\
\text { characteristics* }\end{array}$ & \multicolumn{2}{c}{$56(19.63)$} \\
\hline Age (SD) & 96 women $(70)$ & 41 men (30) \\
Gender (\%) & $7.1(2.5)$ & $1.3(2.6)$ \\
Intensity of pain (SD) & & \\
\hline${ }^{*} n=137$ patients. & & \\
SD: standard deviation. & &
\end{tabular}

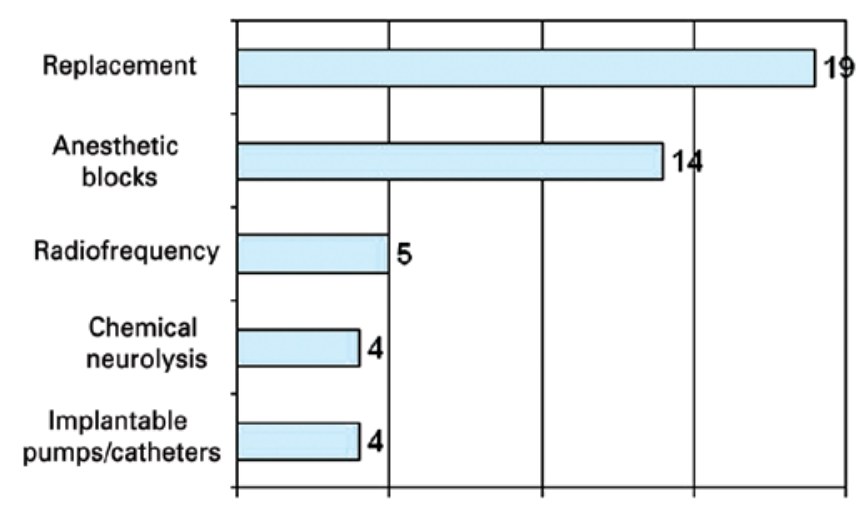

Figure 1. Distribution of types of procedures done

In most of cancer patient $(96 \%)$ procedures was done aiming to relief pain associated with tumor invasion and, in the remaining $4 \%$ the goal was to manage cancer-related pain diagnosis and treatment.

A total of 42 procedures $(90 \%)$ could be defined as the non-neurolytic type (performed without anesthesia). The main primary sites of the disease in patients submitted to procedures were: breast cancer (4; 28.6\%), prostate cancer $(3 ; 21.4 \%)$, lung cancer (2; $14.3 \%)$, pancreatic cancer $(2 ; 14,3 \%)$, lymphoma $(1 ; 7.1 \%)$, myeloma $(1 ; 7.1 \%)$ and head and neck cancer $(1 ; 7,1 \%)$. Such data show the broad applicability and efficacy of interventional procedures in different sites or pathologies.

\section{DISCUSSION}

The findings in this brief study regarding reduction of intensity of pain and the use of opioids are consistent with previous evidences that described the efficacy of interventional procedures for pain, practices already stated for several types of pain, including cancer pain ${ }^{(3,5-8,12,14)}$. Besides, a number of guidelines were established to describe indications, the value of interventional procedures to reduce intensity of pain and the use of analgesic and opioids by other routes, not oral or injection, and also the reduction of side effects of these drugs in patients with cancer pain ${ }^{(3,8,9)}$.
When we collected data for this article, the HIAE did not have a protocol with indication for interventional procedures for pain control, so international guidelines served as the criteria for the interventions ${ }^{(3,8,9)}$. These guidelines stated that indications for these procedures must be based on clinical criteria, consider the type and site of the pain, the cancer stage, the presence of emotional issues, the resources available and life expectancy. In general, interventional procedures are indicated when analgesic administration does not work or when side effects are intolerable. These procedures are contraindicated in case of infection and coagulation changes ${ }^{(3,6-8)}$.

These procedures are in accordance with standards recommended in the literature, which suggest the use of non-ablative procedures that do not destroy the nervous system or the nociceptive pathways ${ }^{(3,7-9,12,14,15)}$. In addition, neurolytic blocks, infusion pumps and catheters are usually indicated for cancer patients. It is important to emphasize that invasive procedures like neurolytic blocks, if available, must be considered an option or complement to pharmacotherapy in any phase of the disease in patients with moderate or severe cancer-related pain $^{(3,6,9)}$.

These procedures benefits are adequate for pain control, reduction or suspension of the use of analgesic and its side effects, and consequently, improve the patient's quality of life and satisfaction. The results of this study showed that these procedures could be used in patients with different types of cancer.

Because at HIAE the total of cancer patients treated is unknown, the percentage of treated individuals with interventional procedures could not be established. However, considering that the probable number of cancer patients treated at HIAE is more than a hundred and the small number of cancer patients treated with interventional procedures between August 2007 and October 2008, we can guess that there is an underuse of minimally invasive procedures in this population, particularly because according to the literature around $10 \%$ of cancer patients will require interventional procedures to pain control ${ }^{(3)}$.

Perhaps the need for reviewing the WHO analgesic ladder, the relatively early use of such techniques in Brazil, the lack of knowledge of these interventional techniques indication, and also the concern of complications explain the underuse of such procedures $^{(3,7,9,10)}$.

This study has limitations which include the lack of assessment between age and gender in the sample, and because it was a small and experimental study we 
evaluated only interventions related to pain. However, as far as we know, such aspects were not reported in international literature.

We attempted to describe the number and type of procedures of interventional medicine done for different types of pain in cancer patients assisted at HIAE, emphasizing mainly the reasons reported by them of strong intensity pain that did not achieve any improve using other pharmacological techniques.

Some benefits as decrease of intensity of pain and in the use of systemic opioids in this population were observed, which suggested an improvement in patients' quality of life and support the efficacy of these techniques.

Current guidelines suggest that such procedures must be indicated at any phase of cancer, not only as the last resource. We think that educational strategies can increase early indication of these interventional procedures. As the efficacy of these interventions is observed by both patients and physicians, and reports with good results are published, many new procedures could be offered in a more systematic way.

\section{CONCLUSION}

These results are in accordance with the literature and support the efficacy of interventional procedures for several types of cancer pain.

\section{REFERENCES}

1. International Association for the Study of Pain. Epidemiology of cancer pain. Seatle: IASP; 2009.

2. International Association for the Study of Pain. Cancer pain. Seattle: IASP; 2009.

3. International Association for the Study of Pain. Cancer pain treatment Seattle: IASP; 2009.

4. World Health Organization (WHO). Cancer pain relief and palliative care. Geneva: WHO; 1990

5. Christo PJ, Mazloomdoost D. Interventional pain treatments for cancer pain. Ann N Y Acad Sci. 2008;1138:299-328.

6. Tay W, Ho KY. The role of interventional therapies in cancer pain management. Ann Acad Med Singapore. 2009;38(11):989-97.

7. Minson FP, Garcia JB, Oliveira JO, Siqueira JT, Jales JH, editores. II Consenso Nacional de Dor Oncológica. São Paulo: Grupo Editorial Moreira Junior; 2011. Tratamento não farmacológico da dor oncológica; p. 92-106.

8. World Health Organization (WHO). Cancer pain relief with a guide to opioid availability. Geneva: WHO; 1996.

9. Eisenberg E, Marinangeli F, Birkhahn J, Paladini A, Varrassi G. Time to Modify the WHO Analgesic Ladder? Pain Clin Updates. 2005;13(5):1-4.

10. Soyannwo A0. Cancer pain management in developing countries. Pain Clin Updates. 2009;17(1):1-4.

11. Boswell MV, Shah RV, Everett CR, Sehgal N, Mckenzie Brown AM, Abdi S, et al. Interventional techniques in the management of chronic spinal pain: evidence-based practice guidelines. Pain Physician. 2005;8(1):1-47.

12. Kedlaya $D$, Reynolds $L$, Waldman S. Epidural and intrathecal analgesia for cancer pain. Best Pract Res Clin Anesthesiol. 1996;16(4):651-65.

13. Von Korff M, Dworkin SF, Le Resche L. Graded chronic pain status: an epidemiologic evaluation. Pain. 1990;40(3):279-91.

14. Koyyalagunta D, Mazloomdoost D. Radiofrequency and cryoablation for cancer pain. Tech Reg Anesth Pain Manag. 2010;14(1):3-9.

15. Zech DF, Grond S, Lynch J, Hertel D, Lehmann KA. Validation of World Health Organizations Guidelines for cancer pain relief: a 10-year prospective study. Pain. 1995;63(1):65-76 